\title{
Settlement of the muricid Concholepas concholepas and its relationship with El Niño and coastal upwellings in southern Chile
}

\author{
C. A. Moreno ${ }^{1, *}$, G. Asencio ${ }^{1}$, W. E. Duarte ${ }^{1}$, V. Marín ${ }^{2}$ \\ ${ }^{1}$ Instituto de Ecología y Evolución, Universidad Austral de Chile, Casilla 567, Valdivia, Chile \\ ${ }^{2}$ Depto. Cs. Ecológicas, Facultad de Ciencias, Universidad de Chile, Casilla 653, Santiago, Chile
}

\begin{abstract}
The settlement of Concholepas concholepas (Brugière, 1789) (Gastropoda; Muricidae) was monitored in the intertidal zone in front of the Marine Reserve of Mehuin in Maiquillahue Bay, south-central Chile, from 1989 to 1997 Data appeared correlated to the SOI (Southern Oscillation. Index) and the occurrence of local upwelling as detected from satellite images. Greatest settlement density was linked to the coupling of upwelling between February and April, coinciding with the occurrence of the first stages of larval development (which hatch from benthic capsules as a late veliger stage). These conditions co-occur when the mean value of the SOI over the 3 mo prior to the beginning of the settlement period approximates zero.
\end{abstract}

KEY WORDS: Settlement - Recruitment - Concholepas concholepas - El Niño Upwellng Chile

\section{INTRODUCTION}

Pelagic larvae of meroplanktonic organisms are influenced by many factors affecting their mortality. These factors (e.g. lack of food, competitors, predators, advection) represent sources of variability for the recruitment process (Thorson 1950, Young \& Chia 1987). They further determine, to a great extent, the demographic characteristics of adult, open populations (sensu Roughgarden et al. 1988)

Studies on the muricid Concholepas concholepas (Brugière, 1789) have shown that it has an epineustonic larva at the stage when it is competent to settle (DiSalvo 1988). The larvae dispersal mechanism seems to be related to the dynamics of the ocean surface winds (Moreno et al. 1993a). This would determine the settlement period and timing of the density patterns in the intertidal benthos and would partially explain the observed variability among years in the density of settlement. Changes in wind stress can, however, be the result of local phenomena (e.g. daily variation related to sea-breeze changes; Marín et al.

•E-mail: cmoreno@uach.cl
1993), or large-scale phenomena like the El Niño Southern Oscillation (ENSO) (Gill 1982). Nevertheless, independent of its origin, the variability in local wind stress near the coast generates features of circulation such as surface drift currents and coastal upwelling (Mann \& Lazier 1991). In turn, coastal upwelling is responsible for nutrient enrichment and the high biological productivity of coastal areas (Mann \& Lazier 1991, Marín et al. 1993, Thomas et al. 1994) and consequently for a 'bottom-up' effect through the food chain (Sherman 1995). Furthermore, coastal upwelling may be an important dispersive force for planktonic organisms living in coastal waters (Marín 1997). If coastal upwellings generate favourable conditions for the survival of the $C$. concholepas larvae, then the question of how large-scale ENSO events modify the local coastal upwelling is relevant for understanding the process of recruitment in this species. If ENSO events are associated with changes in the local coastal upwelling regime, then there are implications for management of the $C$. concholepas fishery and for community impacts in rocky intertidal habitats.

In this paper, we show the results of our search for relationships between the larval settlement of Con- 
cholepas concholepas, ENSO phenomena and the presence of upwelling events off the rocky coast of the Marine Reserve of Mehuin at Maiquillahue Bay (southern Chile).

\section{MATERIAL AND METHODS}

The settlement of Concholepas concholepas was measured on the rocky shore of the Mehuin Marine Reserve (MMR) $\left(39^{\circ} 25^{\prime} 28^{\prime \prime} \mathrm{S}, 73^{\circ} 13^{\prime} 5^{\prime \prime} \mathrm{W}\right)$ located at Maiquillahue Bay, $60 \mathrm{~km} \mathrm{NW}$ of Valdivia. In this area, the density and size structure of the C. concholepas population have been recorded periodically since 1984. Settlement of this species in this rocky area has been measured monthly in 45 fixed plots of $1 \mathrm{~m}^{2}$ each (details in Moreno et al. 1993b). Following the same field protocol used before (Moreno et al. 1993b), we recorded all the individuals present in each of 45 plots, searching on all surfaces and in all pools and crevices in each $1 \mathrm{~m}^{2}$ plot. We considered new settlers to be those from the end of larvae metamorphosis $(1.8 \mathrm{~mm}$ in diameter) to a size of $3 \mathrm{~mm}$ peristomatic length (PL) These sizes correspond to individuals of less than a month old since settling.

Monthly standardized ENSO index (SOI) values were obtained from the NOAA Climate Diagnostics Bulletin. The SOI is derived by subtracting the normalised monthly mean pressure differential at Darwin (Australia) from that at Tahiti (French Polynesia). Negative values correspond to warm El Niño events, while positive values correspond to cold La Niña events. This index is a good indicator of the conditions of the east- ern South Pacific, which influences most of the weather features on the coast of Chile (Quinn \& Neal 1983). When the index is positive, south winds dominate in the study area; the opposite occurs during the ENSO events, when the north wind is dominant.

The presence of upwelling filaments was studied by using the sea surface temperature (SST) field, derived from satellite images of coastal waters from $77^{\circ} 30^{\prime}$ to $68^{\circ} 7^{\prime} \mathrm{W}$ and from $45^{\circ} 47^{\prime}$ to $36^{\circ} 6^{\prime} \mathrm{S}$. We looked for images during the months in which larvae of Concholepas concholepas are in the zooplankton (March to May), during a period of 7 yr (1990 to 1996). Cold upwelling water was characterised as having a temperature range of between 9 and $10^{\circ} \mathrm{C}$, compared to normal SST values of 12 to $14^{\circ} \mathrm{C}$. Satellite information originated from the J-Satellite of the NOAA AVHRR series. Images were geo-referenced at the Centro de Estudios Espaciales, Universidad de Chile (Santiago). Data were gathered and analysed using the geographic information system Idrisi (Eastman 1995).

\section{RESULTS}

\section{Settlement}

There were virtually no recruits during 1992, 1993, 1995 and 1997 (Fig. 1). The coefficient of variation among years was $144.2 \%$. This annual variation is greater than the spatial variation along the shoreline. For instance, during 1991 Moreno et al. (1993b) found, at 12 sites along the regional coast, a CV of $17.6 \%$; during 1996, the CV was $65.6 \%$. In all cases, data were

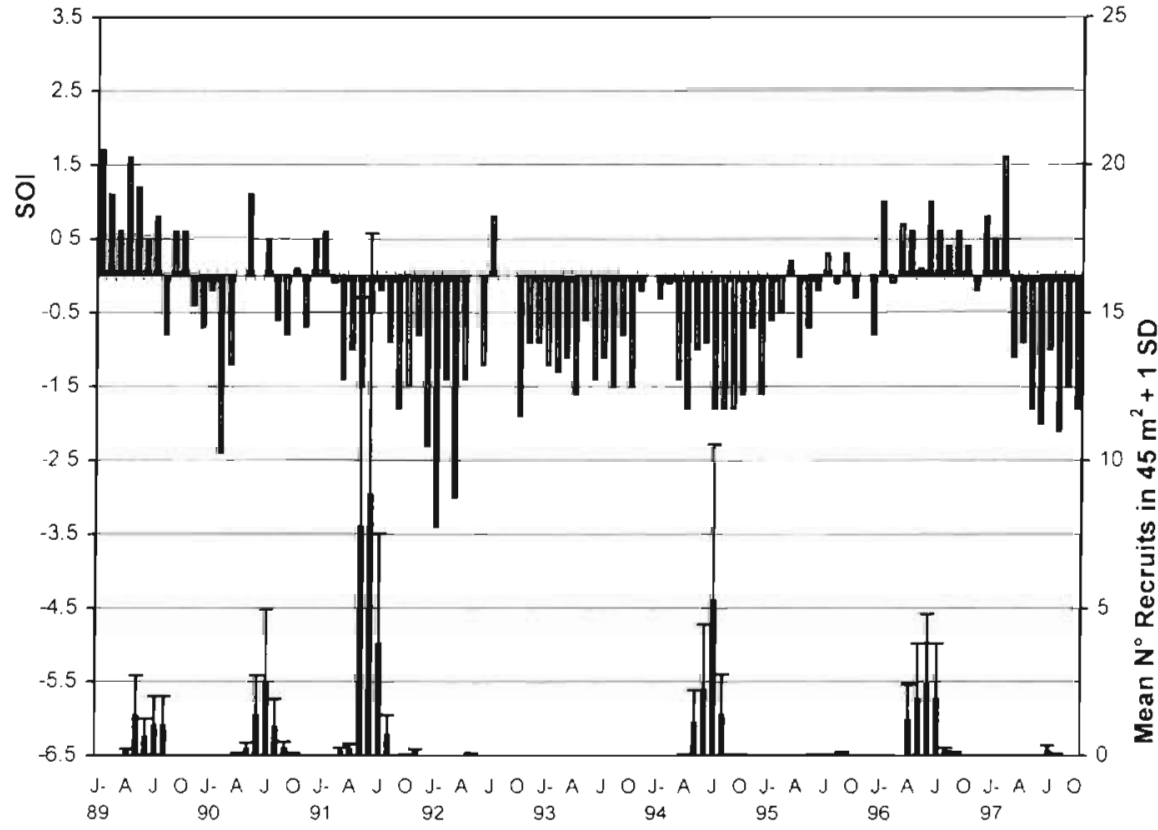

Fig. 1 Monthly standardized Southern Oscillation Index (SOI) values between January 1989 and October 1997 (upper part), and monthly mean (+1 SD) number of Concholepas concholepas settlers in $45 \mathrm{~m}^{2}$ at the Mehuin Marine Reserve, Chile (lower part) 
obtained from at least 10 plots per locality; there were 12 localities along $360 \mathrm{~km}$ of coastline.

\section{The ENSO index (SOI)}

During 1989 and 1996, La Niña years were observed (Fig. 1). From 1992 to 1995, a tendency to El Niño was registered and 1997 was a strong El Niño year. Settlement was not correlated with the index (Pearson's $\mathrm{r}=0.007, \mathrm{p}>$ $0.5)$. A clear picture can be obtained using the average value of the SOI for the 3 mo before settlement begins (Fig. 2). Our observations suggest that settlement does not occur when SOI values are extreme. Fig. 2 also shows that the values have a Gaussian distribution, centred on an SOI value of 0.02874 , with a variance of 0.278 .

\section{Coastal upwelling filaments}

Seven satellite images taken during March were used to study the relationship between coastal upwelling and larval settlement. The peak of settlement occurs during June and July at the study site; thus, March represents, on average, the time at which larvae have already been released from benthic capsules into the water and are in the first month of their pelagic phase. March also corresponds to the onset of autumn and the weather is usually cloudy and rainy, with predominance of north winds during El Niño years (negative SOI values). Dominance of south winds during this period occurs during years with positive SOI values. Images for the only 3 years of successful settlement (1991, 1994 and 1996) showed the presence of upwelling (Fig. 3). As expected, they corresponded to those years in which settlers were found in greater numbers in the 45 plots at the MMR. There seems to be a positive relationship between the area covered by the upwelling water and the total number of settlers of Concholepas concholepas detected in the MMR (Fig. 3). The number of observations is, however, far too small $(n=3)$ to have any statistical confidence in this result.

\section{DISCUSSION}

Large-scale ENSO events do not seem to affect populations of adult benthic invertebrates on the centralsouthern Chilean coast, as may be observed in the northern part of Chile and Perú (Castilla \& Camus

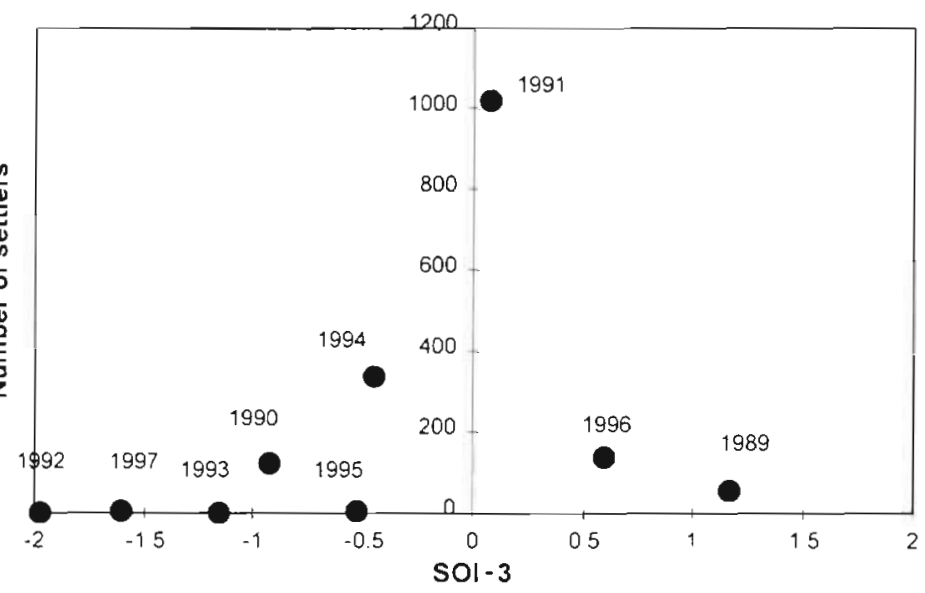

Fig. 2. Relationship between the mean SOl of the 3 mo before the beginning of settlement each year ('SOI-3'), and the total number of ettlers accumulated per year, in the 45 plots at the Mehuin Marine Reserve, 1989 to 1997

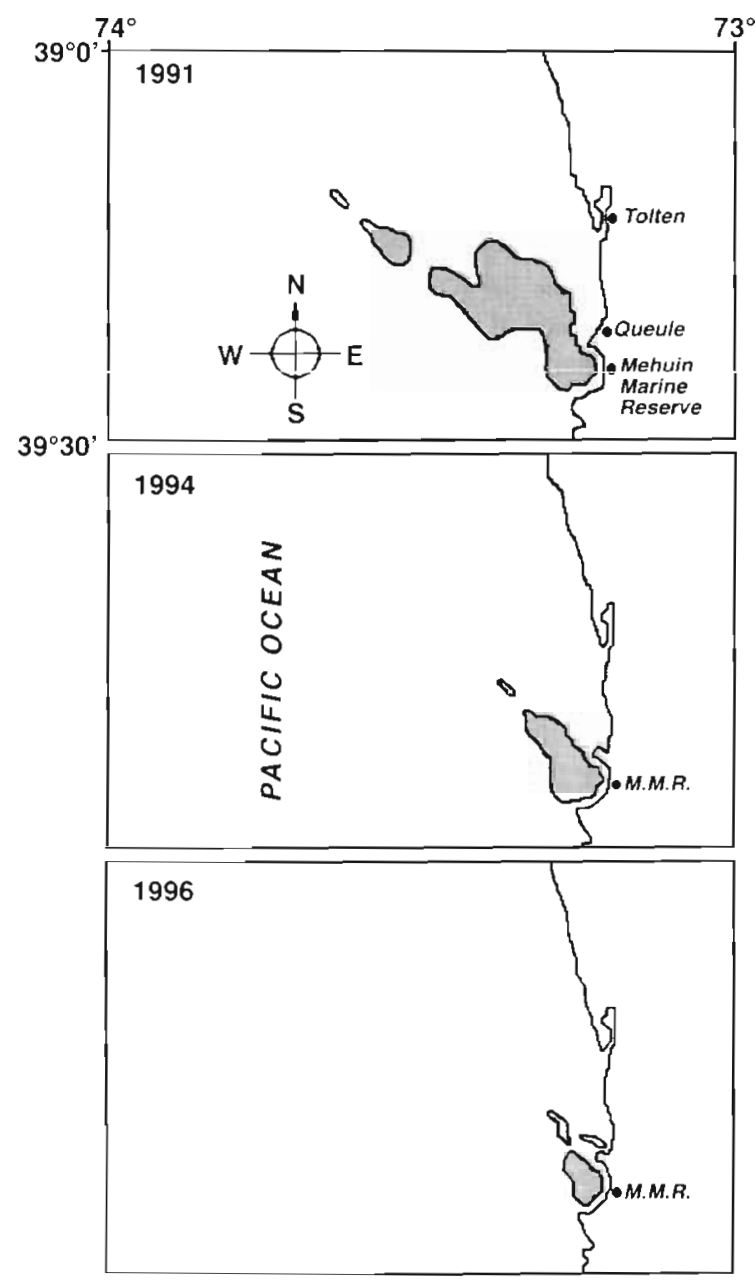

Fig. 3. Presence of upwellings of 9 to $10^{\circ} \mathrm{C}$ (shaded areas) detected during March-April in the coastal area of Maiquillahue Bay in front of the Marine Reserve of Mehuin: SST was 12 to $14^{\circ} \mathrm{C}$ during this period. In 1992, 1993 and 1995 upwellings were not detected in this area with the satellite survey 
1992, Arntz et al. 1998). Nevertheless, Moreno et al. (1993a) showed that settlement of competent larvae of Concholepas concholepas is associated with the presence of autumn northern wind and, consequently, is influenced by interannual climatic changes. Moreover, failures of recruitment described for this important commercial mollusc between $38^{\circ}$ and $41^{\circ} \mathrm{S}$ (Moreno \& Reyes 1988) were suspected to be related to ENSO events (Moreno et al. 1993a).

Our findings show that variability in recruitment is associated with ENSO phenomena. Surprisingly, good settling years were those with SOI values close to zero and bad years those with extreme positive or negative values. Which processes related to ENSO are influencing larval survival? To explore this critical question, using a bottom-up approach, a starting point must be the physical conditions that improve habitat resources for larval survival, e.g. nutrient enrichment.

Variability in settlement seems to be related to ENSO index values 3 mo prior to settlement (SOI-3). That period corresponds to the planktonic phase of Concholepas concholepas (DiSalvo 1988). Positive larval settlement occurs when SOI-3 values are greater than -1 and smaller than +1 , with a mean close to zero. In contrast, when recruitment fails, SOI- 3 values are much smaller than -1 or greater than +1 . SOI -3 values smaller than -1 indicate that an ENSO warm event is present; when SOI -3 reaches -2 the phenomenon can be considered as very strong. Under such conditions, the study area is cloudy and rainy and a north wind component is dominant for most of the year. On the other hand, when the index is positive, high atmospheric pressure, clear skies and a south wind component are dominant. We have found that the 3 mo period before settlement begins is characterised by a switch between positive and negative SOI values. We believe that during 'normal years' coastal water circulation is very dynamic, switching between upwelling and downwelling.

The condition previously described occurs with greater frequency in southern than in northern Chile. When it happens, it is followed by an increase in phytoplankton pigment in the sea surface (Thomas et al. 1994). In spite of the fact that the flux is mainly directed away from the shore (towards the northwest) there are minor inshore fluxes. We infer that the latter may exert a large influence on the coastal ecosystem. Our results show the presence of upwelling during the years 1991, 1994 and 1996, corresponding with years of better settlement. The most intensive upwelling event during our sampling was in March 1991, when the area covered by upwelling water extended about $54 \mathrm{~km}$ offshore. Correspondingly, larval settlement that year was the most dense and most extensive known for this area between 1989 and 1997.
If this condition, i.e. intensive upwelling with an influence towards the coast, followed by the development of a phytoplankton bloom, generates a cascade effect across the local food chain, then conditions favorable for the survival of Concholepas concholepas may prevail. In this period of the year, a large proportion of larvae are in the water column eating phytoplankton. A greater abundance of phytoplankton, especially large diatoms like Chaetoceros spp. (encountered in gut contents of the competent larvae; $\mathrm{C}$. Moreno pers. obs.), can be related to the presence of nutrients resuspended by the upwelling in this area in the months before settlement. However, there could also be subsidiary elements that can produce an enrichment of the coastal waters, such as organic debris provided by subtidal macroalgae, as has been described for Nova Scotia, Canada, by Mann (1972) and for South Africa by Bustamante et al. (1995). Future studies concerning productivity of coastal waters must segregate the relative importance of each source.

Additionally, larvae need to be transported to the rocky shore habitats in which the adult population lives. The known mechanism of transport seems to be related to the presence of north winds (Moreno et al. 1993a). Thus, the successful recruitment of larvae, under the proposed mechanism, requires a coupling between 2 opposite phenomena: upwelling generated by south winds, followed by a relaxation period and the transport of surface waters towards the coast by north winds. These climatic changes occur frequently during the transition between summer and fall, and are also responsible for generating large phytoplankton blooms in other areas along the Chilean coast (Marín et al. 1993). The life history of Concholepas concholepas in the study area seems to be connected with these oceanographic phenomena. Capsules are laid mostly in November and December (Lépez 1987). Intracapsular development takes about 35 d (Gallardo 1973) and larvae spend at least 3 to 4 mo in the plankton (Moreno et al. 1993a). Then, for successful recruitment to occur there must be an alternate sequence of south and north winds during March or April. This must start with south winds, when larvae are released from capsules, and the sequence must finish with north winds, at the time when competent veliger larvae are almost ready to settle. If this happens, the presence of extreme El Niño or La Niña will not only affect the local weather but also may preclude the appropriate sequence of events, producing a failure of recruitment, as described by Moreno \& Reyes (1988).

Acknowledgements. We thank Jorge Guerra and Rodrigo Reyes for help in collecting field data and José E. Castro from the Centro de Estudios Espaciales in Santiago for his help in the selection of the satellite images and the specialized software. We also thank the referees for their interesting and use- 
ful comments and suggestions that improved the manuscript. This paper was partially funded by the projects Fondecyt 1951191 and FONDAP O\&BM No. 3.

\section{LITERATURE CITED}

Arntz WE, Valdivia E, Zeballos J (1988) Impact of El Niño 1982-83 on the commercially exploited invertebrates (mariscos) of the Peruvian shore. Meeresforschung 32(1): $3-23$

Bustamante RH, Branch GM, Eekhout S (1995) Maintenance of an exceptional intertidal grazers biomass in South Africa: subsidy by subtidal kelps. Ecology $76(7)$ : $2314-2329$

Castilla JC, Camus PA (1992) The Humboldt-El Nino Scenario: coastal benthic resources and anthropogenic influences, with particular reference to the $1982 / 83$ ENSO. S Afr J Mar Sci 12:703-712

DiSalvo LH (1988) Observations on the larval and post-metamorphic life of Concholepas concholepas (Brugière, 1789) in laboratory culture. Veliger 30:358-368

Eastman JR (1995) Idrisi for Windows. Clark University, Worcester, MA

Gallardo C (1973) Desarrollo intracapsular del Concholepas concholepas (Brugière) (Gastropoda Muricidae). Mus Nac Hist Nat Publ Ocas (Santiage de Chile) 16:3-16

Gill AE (1982) Atmosphere-ocean dynamics. International Geophysics Series, Vol 30. Academic PIess, New York

Lépez Ml (1987) Ecología intermareal de Concholepas concholepas (Brugière, 1789) bajo dos regimenes de intervención antrópica. Tesis Magister en Ciencias mención Ecología, Facultad de Ciencias, Universidad Austral de Chile, Valdivia

Mann KH (1972) Ecological energetics of the seaweed zone in a marine bay on the Atlantic coast of Canada. II. Productivity of the seaweeds. Mar Biol 14:199-209

Mann KH, Lazier JR (1991) Dynamics of marine ecosystems. Biological-physical interactions in the oceans. Blackwell, Oxford

Editorial responsibility: Otto Kinne (Editor),

Oldendorf/Luhe, Germany
Marin V (1997) A simple-biology, stage-structured population model of the spring dynamics of Calanus chlensis at Mejillones del Sur Bay, Chile. Ecol Model 105:65-82

Marín V, Rodríguez L, Vallejo L, Fuenteseca J, Oyarce E (1993) Dinámica primaveral de la productividad primaria de Bahia Mejillones del Sur. (Antofagasta, Chile). Rev Chil Hist Nat 66(4):479-491

Moreno CA, Asencio G, Ibañez S (1993a) Patrones de asentamiento de Concholepas concholepas (Brugière) (Mollusca: Muricidae) en la zona intermarea! rocosa de Valdivia, Chile. Rev Chil Hist Nat 66:93-101

Moreno CA, Reyes A (1988) Densidad de Concholepas concholepas (Brugière, 1789) (Gastropoda: Muricidae) en la Reserva Marina de Mehuın. Evidencias de fallas en el reclutamiento. Biol Pesq (Chile) 17:31-38

Moreno CA, Reyes A, Asencio G (1993b) Habitat and movements of the recruits of Concholepas concholepas (Mollusca; Muricidae) in the rocky intertidal of southern Chile. J Exp Mar Biol Ecol 171:51-61

Quinn W, Neal V (1983) Long-term variation in the southern oscillation, El Nino, and Chilean subtropical rainfall. Fish Bull 81(2):363-374

Roughgarden JS, Gaines S, Possingham H (1988) Recruitment dynamics in complex life cycles. Science 241:1460-1466

Sherman K (1995) Large marine ecosystems and fisheries. In: Munasinghe $M$, Shearer $W$ (eds) Defining and measuring sustainability. The biogeophysical foundations. The United Nations University and the World Bank, Washington, DC, p 207-233

Thomas AC, Strub PT, Huang F, James C (1994) Comparison of the seasonal and interannual variability of phytoplankton pigment concentration in the Peru and California current systems. J Geophys Res 99(C4):7355-7370

Thorson G (1950) Reproduction and larval ecology of manne bottom invertebrates. Biol Rev 25:1-45

Young CM, Chia FC (1987) Abundance and distribution of pelagic larvae as influenced by predation, behaviour, and hydrographic factors. In: Giese AC, Pearse JS, Pearse VB (eds) Reproduction of marine invertebrates, Vol 9. Blackwell, Palo Alto, p 385-461

Submitted: December 17, 1997; Accepted: April 6, 1998 Proofs received from author(s): June 2, 1998 